\title{
El intertexto genérico en el documental latinoamericano contemporáneo
}

\author{
Pablo Lanza
}

\author{
Recibido: 30.10.2020 — Aceptado: 25.11.2020
}

\section{Titre / Title/ Titolo}

L'intertext générique dans le documentaire latino-américain contemporain The Generic Intertext in Contemporary Latin American Documentary L'intertesto generico nel documentario latinoamericano contemporaneo

\section{Resumen / Résumé / Abstract / Riassunto}

En las últimas décadas los estudios sobre el cine documental han hecho hincapié en el progresivo borramiento de las fronteras con la ficción y caracterizaron a las producciones como objetos híbridos. Si bien estas líneas nunca fueron tan rígidas como suele señalarse, es cierto que el alto nivel de estilización se ha convertido en una constante del documental actual. El presente artículo analiza una serie de documentales latinoamericanos producidos en las últimas dos décadas a partir del diálogo que los films establecen con distintos géneros cinematográficos: el cine de terror, la road movie, y el film noir. La apropiación de estructuras narrativas, procedimientos e iconografías de los distintos géneros le proporciona al documental una serie de herramientas claves para la transmisión de historias personales y colectivas.

Au cours des dernières décennies, les études sur le cinéma documentaire ont mis l'accent sur le brouillage progressif des frontières avec la fiction et caractérisé les productions comme des objets hybrides. Bien que ces lignes n'aient jamais été aussi rigides qu'on le note souvent, il est vrai que le haut niveau de stylisation est devenu une constante dans le documentaire d'aujourd'hui. Cet article analyse une série de documentaires latino-américains produits au cours des deux dernières décennies à partir du dialogue que les films établissent avec différents genres cinématographiques: cinéma d'horreur, road movie et film noir. L'appropriation des structures narratives, des procédures et des iconographies des différents genres fournit au documentaire une série d'outils clés pour la transmission d'histoires personnelles et collectives.

In the last decades, studies on documentary cinema have emphasized the progressive blurring of borders with fiction works and characterized such productions as hybrid objects. Even though the borders between the two domains were never as rigid as it is often pointed out, it is true that a high degree of stylization has become a constant feature in contemporary documentary film. This article analyzes a number of Latin American documentaries produced in the last two decades by taking into account the dialogue the films establish with different cinematographic genres: horror cinema, road movie and film noir. The appropriation of narrative structures, procedures and iconographies of the different genres provides documentaries with a series of key tools for the articulation of personal and collective stories.

Negli ultimi decenni, gli studi sul cinema documentario hanno evidenziato il progressivo offuscamento dei confini con la fiction e caratterizzato tali produzioni come oggetti ibridi. Anche se le linee tra i due ambiti non sono mai state così rigide come spesso si segnala, è vero che un alto livello di stilizzazione è diventato una costante nel documentario attuale. Questo articolo analizza una serie di documentari latinoamericani prodotti negli ultimi due decenni a partire dal dialogo che tali film instaurano con diversi generi cinematografici: cinema horror, road movie e film noir. L'appropriazione di strutture narrative, procedure e iconografie dei diversi generi fornisce ai documentari una serie di strumenti chiave per la trasmissione di storie personali e collettive.

\section{Palabras clave I Mots-clé I Key words IParole chiave}

Cine documental, géneros cinematográficos, hibridación, América latina, intertexto.

Film documentaire, genres cinématographiques, hybridation, Amérique latine, intertext.

Documentary film, film genres, hybridization, Latin America, intertext.

Film documentario, generi cinematografici, ibridazione, America Latina, intertesto. 
Documental y ficción han sido tradicionalmente abordados como poéticas opuestas. Desde sus orígenes, algunos de sus principales realizadores y teóricos remarcaron las diferencias entre ambos como una forma de posicionamiento. ${ }^{1}$ No obstante, en ninguna etapa de sus respectivas historias, el cine documental y el de ficción se caracterizaron por la pureza, incluso en las obras de aquellos que tomaban una posición fuerte en sus escritos. En este sentido, podemos afirmar que tanto el cine de ficción como el documental se han caracterizado en distintos momentos por sus rasgos híbridos. ${ }^{2}$

El teórico Fredric Jameson se refiere a la hibridez como una de las características de la era posmoderna, y compara su funcionamiento con el de un virus para explicarlo:

la hibridación no es una síntesis entre razas o tradiciones, ni un término intermedio o mediador en el que se seleccionan y combinan rasgos de ambos lados de la frontera. (...) En este nuevo proceso posmoderno lo que sucede evidentemente es que se selecciona un único fragmento característico de un gen y se inserta en otro, más o menos como se implanta un virus en una célula (316)

Podemos hacer dos observaciones en relación a este postulado. Primero, que la hibridación no consiste en una amalgama superadora, sino que denomina a una mezcla. Segundo, si la hibridez consiste en la introducción de un elemento foráneo en otro cuerpo, las formas en la que el cine de no ficción puede abordar el intertexto con los géneros son múltiples -personajes, estructuras, iconografías, etc--. Si bien se pueden hallar ejemplos de filmes de carácter híbrido a lo largo de la historia del cine, es decir que no se trata de «un nuevo proceso» exclusivo de la era posmoderna, es cierto que «la hibridación es ahora el rasgo distintivo de la factualidad. Los límites entre realidad y ficción se han lleva-

Robert Flaherty escribía en 1937 que «el filme de espectáculo debe someterse a determinados imperativos de método que invalidan su autenticidad y ocultan la realidad (...) [las cuales] demuestran de forma indirecta las ventajas del documental» (151). En uno de sus más famosos manifiestos, Dziga Vertov, exponía: «NOSOTROS declaramos que los viejos films novelados, teatralizados y demás tienen la lepra» (37).

Para el caso del documental latinoamericano veáse Chanan (2009). do al límite en varios formatos fácticos populares que mezclan géneros de ficción y no ficción» (Hill, 2007: 2).

En este caso nos interesa abordar las formas en las que documentales recientes de América Latina recurren a cierta matriz de los géneros de la ficción cinematográfica en su representación. Esta operación ha sido una constante de las últimas décadas del documental global y la producción latinoamericana no constituye una excepción. ${ }^{3}$ En este sentido, el artículo pretende ser una introducción a la temática y brindar un panorama que proporcione ejes posibles de investigación.

Ahora bien, cabe preguntar por qué se produce este tipo de mixtura en el cine de no ficción y cuál es el atractivo del cine de género para el mismo. Para intentar contestar estas cuestiones, nos detendremos en algunos aspectos de la teoría de los géneros. En su trabajo sobre los géneros retóricos, Carolyn Miller argumenta que el entendimiento de los mismos puede «ayudar a explicar la forma en que encontramos, interpretamos, reaccionamos y creamos textos particulares» (151). Esto se relaciona con la importancia de la clasificación y la tipificación y, en este sentido, los géneros constituyen un aspecto clave de la racionalidad cultural. En el caso de los géneros cinematográficos, nos interesa señalar un funcionamiento similar: el reconocimiento de sus características ofrece indicadores a los espectadores sobre cómo interpretar los objetos culturales a la vez que permiten vincularlos a lo comunal. La relevancia de los géneros en nuestras culturas, entendidos estos como fenómenos transnacionales (o de la globalización), han incidido en las formas en la que los seres nos relacionamos con el mundo y nuestros pares.

El cine popular de ficción ha sido tradicionalmente agrupado en torno a géneros, entendidos como categorías, que el público reconoce con relativa facilidad, por lo que han funcionado como una de las herra-

Alisa Lebow señala al respecto, «el documental del siglo XXI encontró la receta del éxito siguiendo las fórmulas de las películas de género de ficción. Man on Wire (género de atracos) ganó el Oscar a la Mejor Película Documental en 2009, In the Shadow of the Moon (género de ciencia ficción), ganó el Premio del Público de Cine Mundial del Festival de Sundance en 2007 y Paradise Lost 3: Purgatory (género judicial) fue nominada a un Premio de la Academia en 2011, por nombrar solo algunas» (472). 
mientas más efectivas de publicidad para los filmes. Sin embargo, los géneros no constituyen categorías fijas y han probado ser difíciles de definir. Rick Altman, autor de uno de los trabajos más influyentes sobre la temática, propone un sistema de análisis de los géneros al que denomina semántico-sintáctico-pragmático. El enfoque semántico «se centra en los bloques constructivos del género, mientras que la perspectiva sintáctica privilegia las estructuras en que éstos se disponen» (296), y el abordaje pragmático analiza el contexto sociocultural particular; es decir, propone una fusión de temas y estructuras con su contexto. Dado que nuestro corpus no pertenece justamente a un género, ni puede enmarcarse dentro de una industria cultural, sino que trabaja sobre la apropiación de algunos de sus elementos tanto sintácticos como semánticos, recuperaremos algunos aspectos de esta propuesta y dejaremos de lado otros.

Altman observa que los géneros cinematográficos son fáciles de mezclar ya que la concepción popular de los mismos suele relacionarse a uno o dos elementos, «lo que permite evocar al género con un material mínimo» (181). Justamente el término hibridación permitiría dar cuenta de su carácter mutante, ${ }^{4}$ es decir que en términos representacionales su naturaleza es impura. Por supuesto que el documental, como ya mencionamos, también posee estas posibilidades de combinación, y las has practicado desde los primeros largometrajes de Robert Flaherty. Sin embargo, esto no niega su existencia como objeto, ni equivale su condición a la ficción. Como señalara Jacques Rancière para la película documental «lo real no es un efecto que producir, sino un dato que comprender. El filme documental puede entonces aislar el trabajo artístico de la ficción disociándolo de eso a lo que se acostumbra a asimilar: la producción imaginaria de verosimilitudes y efectos de realidad» (183). Si bien no coincidimos con su postura que considera al documental como «una modalidad de ficción» (183), la

\footnotetext{
${ }^{4}$ Janet Staiger (2012) propone hablar de endogamia para la combinación de géneros en filmes de ficción, ya que no esta no implica el diálogo entre dos objetos de naturaleza distinta. Creemos que en la combinación que trabajaremos, el término híbrido es correcto en tanto documental y ficción, si bien pueden compartir elementos, son dos discursos distintos.
}

noción de «aislar el trabajo artístico de la ficción» (183) resulta productiva para nuestro planteo.

Como indican María Guadalupe Arenillas y Michael J. Lazzara (2016), el documental en América Latina ha experimentado una especie de boom en las dos últimas décadas, marcado por una «innovación sostenida en las prácticas de realización de documentales. Prácticas cada vez más reflexivas y metacinemáticas que difuminan la línea que separa tradicionalmente el documental del cine de ficción» (1-2). En este artículo nos ocuparemos entonces de la hibridación documental-ficción a partir del intertexto con el cine de géneros en América Latina en el corriente siglo, momento en el que el alto nivel de estilización se ha convertido en una constante del cine de lo real. Para eso nos centraremos en tres modelos: el terror, la road movie y el film noir considerando en cada caso un ejemplo argentino y un segundo de otra nacionalidad. Estos distan de ser los únicos ejemplos de cruces actuales con los géneros, también podemos nombrar documentales que beben del melodrama en filmes como Um passaporte húngaro (Sandra Kogut, 2003, Brasil) y Perdida (Viviana García Besné, 2010, México), el musical con Las enfermeras de Evita (Marcelo Goyeneche, 2015, Argentina) e incluso la ciencia ficción en Branco Sai, Preto Fica (Adirley Queirós, 2014, Brasil). ${ }^{5}$

\section{El miedo es la clave: el documental de terror}

El diálogo entre el cine de terror y el documental no es novedoso. En las formas actuales industriales el subgénero de found footage ha gozado de mucha visibilidad, en especial a partir del estreno de El proyecto de la bruja de Blair (The Blair Witch Project, Eduardo Sánchez y Daniel Myrick, 1999). Sin embargo, este subgénero consiste en filmes ficcionales que utilizan los elementos de la puesta en escena del documental o las home movies, es decir,

\footnotetext{
También en este período el cine de ficción ha entablado un diálogo inverso a partir de las películas basadas en documentales. Dos ejemplos son las brasileñas Ônibus 174 (José Padilha, 2002) y Última parada 174 (Bruno Barreto, 2008) y Man on wire (James Marsh, 2008) y The Walk (Robert Zemeckis, 2015). En ambos casos la recepción de los documentales fue mucho más positiva.
} 
el diálogo inverso al que nos interesa analizar. Probablemente el antecedente documental más reconocido sea La brujería a través de los tiempos (Häxan, Benjamin Christensen, 1922), película silente que alterna entre el documental de carácter expositivo y recreaciones ficcionales para retratar la persecución de brujas durante la inquisición y exponer las creencias de aquel momento.

En el caso del documental latinoamericano, puede observarse un breve conjunto de filmes de los últimos años que abordan estos cruces. Entre ellos podemos mencionar Ataque de pánico (Ernesto Ardito, 2017, Argentina), Alucardos, retrato de un vampiro (Ulises Guzmán Reyes, 2011, México), La libertad del diablo (Everardo González, 2017, México), y el falso documental Filmefobia (Kiko Goifman, 2008, Brasil). Nos focalizaremos, a continuación, en los dos primeros, ejemplos muy disímiles entre sí que recurren a una imaginería y procedimientos de terror con propósitos muy distintos.

Ataque de pánico es la primera realización firmada en solitario por Ernesto Ardito, ${ }^{6}$ y aborda el problema del trastorno de ansiedad en la sociedad actual, una aflicción cada vez más común. Tanto el nombre del filme como su subtítulo, «Esclavos del miedo a la muerte», permiten apreciar un acercamiento a la temática del terror. El documental emplea una amplia gama de recursos estilísticos para exponer la historia de esta enfermedad y analizar las razones de su crecimiento exponencial en la actualidad. Se trata, en parte, de un documental expositivo que hace uso de un relato en voz over que guía la interpretación de las imágenes, a la vez que presenta entrevistas de autoridad a diversos profesionales de la salud. Sin embargo, el tratamiento de las imágenes remite a cierta iconografía que se asocia al género del terror.

El documental presenta testimonios de diversos padecientes del trastorno en cuestión, pero sus rostros no son exhibidos a la cámara, sino que se muestran sus siluetas en habitaciones filmadas en penumbras. Estos relatos son ilustrados con tormentas y sonidos de true-

6 Junto a Vilna Molina, su pareja, la dupla ha realizado una serie de reconocidos documentales -Raimundo, Corazón de fábrica, entre otros-, que pueden enmarcarse dentro de un cine militante social. El caso de Ataque de pánico es particular, en tanto Molina participa en múltiples rubros, pero está firmada por Ardito en solitario.
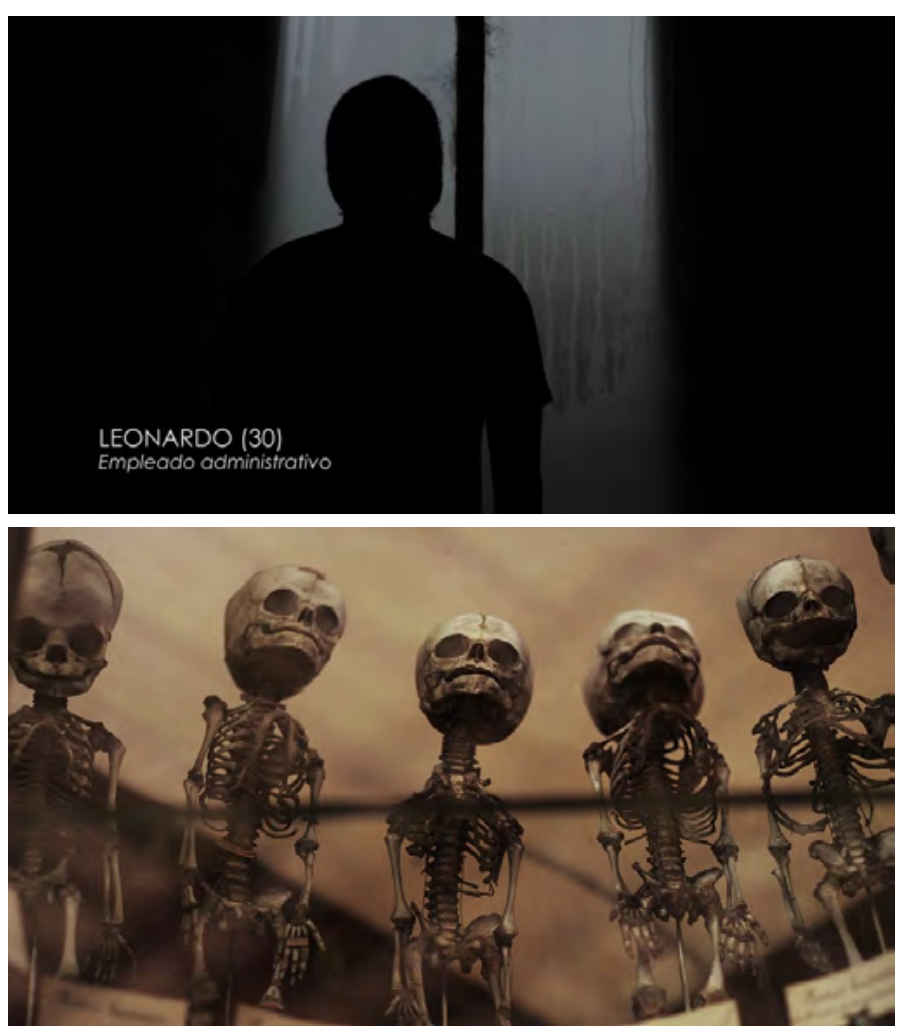

Ataque de pánico (Ernesto Ardito, 2017)

nos, planos acelerados de la ciudad y de hospitales. De forma llamativa, Ardito no apela a reconstrucciones para exponer los episodios, sino que recurre a la manipulación de las imágenes cotidianas y la utilización de otras más perturbadoras pertenecientes a la ciencia que adquieren un valor simbólico.

La hipótesis principal del filme es que este trastorno no es individual sino colectivo. El relato over que comienza la película expone los síntomas: «Temblores, ahogo, sudoración, palpitaciones, opresión, náuseas, mareo, despersonalización, escalofríos y sofocaciones. El aumento de estos síntomas y la pérdida de control desencadenada conlleva a creerse morir. A creer tener un infarto, un $\mathrm{ACV}$, o creer volverse locos». A partir del collage sonoro y de imágenes que buscan shockear al espectador, asigna gran parte de estas responsabilidades a los medios de comunicación y el sistema capitalista global. Los ataques de pánico se relacionan con la ansiedad, y el constante bombardeo de noticas trágicas e inseguridad de los medios de 
comunicación y las redes sociales resulta en un exceso de información que mucha gente no puede asimilar. El documental cita una de las más famosas frases del escritor de terror H.P. Lovecraft, «el terror más grande viene de lo que no se ve, lo que no se conoce», el cual se relaciona rápidamente con una de las máximas expuestas por el relato over, «los capitales financieros son invisibles, espectrales, desconocidos y los trabajadores del sector privado dependen absolutamente de ellos». Si la recurrencia al género de terror comenzaba como una forma de transmitir las sensaciones del ataque de pánico, con el transcurso del metraje se convierte en una herramienta de denuncia que termina asignándole a la película el carácter militante habitual de la obra de Ardito.

El documental mexicano Alucardos, retrato de un vampiro es un exponente muy distinto a Ataque de pánico. En este caso, el diálogo con el género de terror es mucho más explícito y no se circunscribe sólo a ciertos procedimientos, sino que se relaciona más explícitamente con la historia narrada. El título hace referencia a la película de culto de terror Alucarda, la bija de las tinieblas (Juan López Moctezuma, 1978) y a dos de sus protagonistas, Lalo Cazares y Manolo Durán, los autodenominados alucardos, en honor al filme. A estas dos historias de vida se suma la biografía de López Moctezuma, una figura notoria de la cultura mexicana de aquella época: conductor de televisión, locutor de radio y productor de filmes como El topo (Alejandro Jodorowsky, 1970). Estas tres líneas narrativas, separadas al comienzo de la película lentamente se entrelazan en una historia, como suele decirse, más extraña que la ficción.
En el caso de la reconstrucción biográfica del realizador, se apela a testimonios de familiares y entrevistas a figuras reconocidas de la cultura mexicana (Carlos Monsiváis y Jorge Ayala Blanco), imágenes de archivos y fragmentos de sus películas para reconstruir su vida. Todas estas secuencias se acomodan a las expectativas de un documental clásico, mientras que las pertenecientes a los alucardos se distinguen por la utilización de reconstrucciones de las experiencias narradas. Manolo, obsesionado con el filme de López Moctezuma desde chico, y Lalo cuentan episodios de su infancia que son escenificados de manera estilizada siguiendo la imaginería del cine de terror. Valga como ejemplo el relato de Lalo cuando vio un cadáver en un hospital, mientras esperaba a su tío que trabajaba ahí. Si bien su relato no posee elementos sobrenaturales, las imágenes del filme muestran a una mujer desnuda caminando por los pasillos vacíos del sanatorio que aparece y desaparece, el niño la sigue hasta llegar a la morgue mientras la banda sonora apela a sonidos aciagos. Una vez ahí, el cuerpo sin vida de una mujer que, como cuenta Lalo, le recordaba a su madre, se exhibe en plena autopsia con las vísceras afuera mientras el niño «Lalo» lo toca, y concluye cuando ella abre los ojos y lo mira. La reconstrucción no coincide exactamente con el relato oral, sino que se asemeja a una especie de pesadilla, pero encuentra su justificación a partir de la fascinación que profesan por la película de terror de López Moctezuma y sus historias de vida: en el caso de Lalo revelará más adelante que su madre fue asesinada por su padre exhibiendo para la cámara las fotos del expediente policial, mientras que Lalo tuvo cierto grado de hermafro-

Alucardos, retrato de un vampiro (Ulises Guzmán Reyes, 2011)
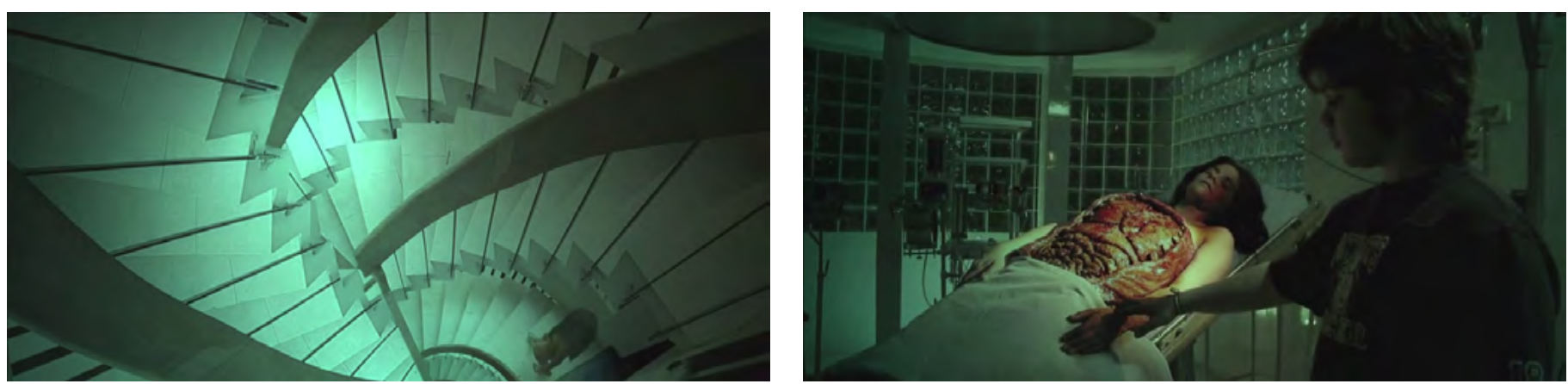
ditismo y episodios de bullying de chico. Estos motivos, como afirman ellos mismos, los convirtieron en parias de la sociedad.

Como mencionamos, todas estas historias terminarán entrecruzándose. Manolo y Lalo trabaron una fuerte amistad, y el primero trasmitió su obsesión por Alucarda, filme al que no pudieron acceder por un largo tiempo. Para ese entonces, López Moctezuma había caído en desgracia por una serie de eventos y se encontraba internado en un psiquiátrico sin tener conocimiento de su identidad. Tras recibir una misteriosa llamada de una supuesta secretaria del director, viajan al hospital y deciden sacar a su ídolo bajo su expreso pedido. Durante este episodio, los dos fanáticos decidieron mostrarle sus películas y llevarlo a las locaciones donde había rodado Alucarda, con Manolo vestido con el atuendo de la protagonista. Sorprendentemente, esto consiguió que López Moctezuma recobrara el conocimiento y que, al morir dos años después, les legara los derechos a su obra. Una vez más, se presentan reconstrucciones estilizadas, e incluso animaciones, para narrar todo esto. Las entrevistas en conjunto a los protagonistas se desarrollan en un bosque, que luego se revelará como el lugar del rodaje y del secuestro, con ellos vestidos de negro como figuras fantasmales.

En una de sus intervenciones, Monsiváis cuenta que, según López Moctezuma, las historias de vampiros «incursionaban en las profundidades de la psiquis». El profundo efecto que la película tuvo en los protagonistas del documental da cuenta del impacto que los géneros cinematográficos pueden tener en las biografías. Manolo dice,

Alucarda fue parte del nexo que nos unió. Porque Alucarda en ese entonces representaba el misterio, la libertad. Le platiqué [a Lalo] que Alucarda tenía una novia, que era Justine, que se enfrentaban al mundo porque el mundo que las rodeaba no estaba de acuerdo con su amor.

Lalo expresa que ellos son Alucarda y Justine, a veces una y a veces otra: «hay una afinidad entre el mundo de Alucarda y el mío». El cine de género, en este caso, muestra su potencial para ser tanto una forma de conexión con otros como una herramienta que permite comprender la posición de uno en el mundo.

En estos ejemplos podemos observar que el terror es reapropiado en el documental a partir de ciertos pro-

Alucardos, retrato de un vampiro (Ulises Guzmán Reyes, 2011)

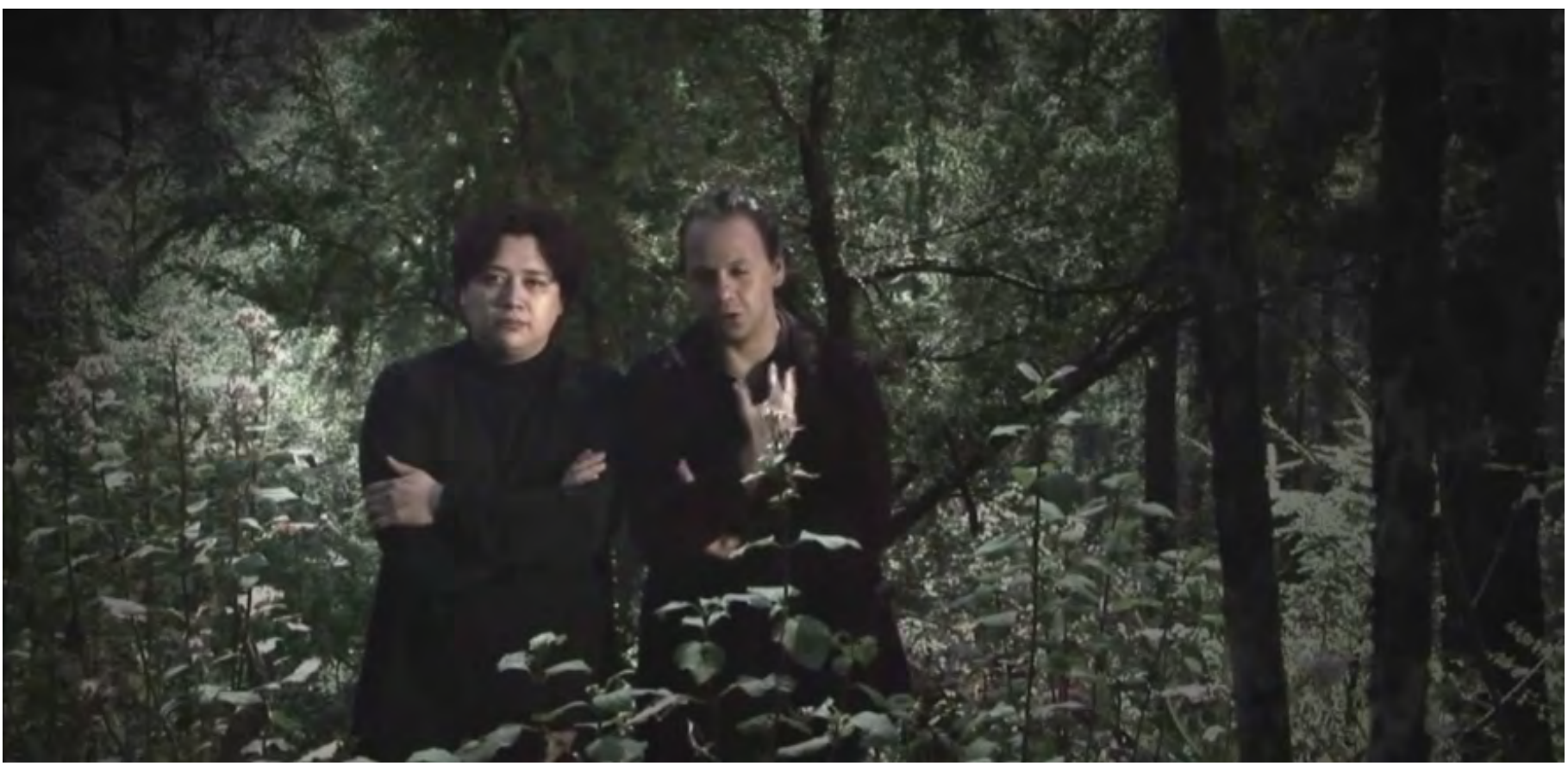


cedimientos, situaciones e imágenes con el objetivo de transmitir sensaciones y climas a los espectadores. El género se convierte así en una herramienta para la comprensión del comportamiento humano.

\section{Los caminos de la vida: el documental y la road movie}

La intersección del documental con el género road movie ha resultado ser una de la más transitadas en la no ficción contemporánea. Como género de ficción, la road movie, suele considerarse más cercano a la modernidad (Corrigan, 1991), si bien pueden encontrarse ejemplos tan tempranos como Lo que sucedió aquella noche (It happened one night, Frank Capra, 1934).

Con respecto al enfoque sintáctico, Devin Orgeron (2008) argumenta que el género se caracterizó históricamente por las aspiraciones de estabilidad y formación de comunidades, estas serán justamente las temáticas de los dos documentales que abordaremos. Pablo Piedras y Nadia Lie mencionan las siguientes características recurrentes del género: «el motivo del viaje, la centralidad del coche, el protagonismo de parejas de personajes o sea buddies y el uso frecuente de travelling shots para evocar la sensación misma del desplazamiento» (79). En el caso de su relación con el documental, como señala Pablo Piedras («The Contemporary Documentary Road Movie»), se puede mencionar como una de las más tempranas modalidades del cine de no ficción los travelogues, las películas sobre viajes y exploraciones, un modelo temático de gran productividad, por lo menos hasta el fin del período silente. En América Latina, la hibridación con el género tal como se practica en los ejemplos a analizar debe ubicarse a comienzos de la década del noventa con el influyente filme The Devil Never Sleeps (El diablo nunca duerme, Lourdes Portillo, 1994) y, en especial en los albores del siglo XXI. ${ }^{7}$

Entre otros múltiples títulos podemos mencionar The illusion (Susana Barriga, 2008, Cuba), Pachamama (Eryk Rocha, 2008, Brasil), Familia tipo (Cecilia Priego, 2009, Argentina), Diario de Uma busca (Flávia Castro, 2010, Brasil), Ciclo (Andrea Martínez Crowther, 2013, México), My Way or the Highway (Silvia Lorenzini, 2017, Colombia) y Las cintas de mi madre (Stefany Cristell Cobián Ramírez, 2019, Perú).
El documental Return to Bolivia (Mariano Raffo, 2008) exhibe un carácter transnacional desde su mismo título, el cual hace referencia no solo al viaje central del filme (Argentina-Bolivia), sino que tiene la peculiar característica de estar escrito en inglés. Probablemente, esto se explique con el subtítulo presente en los carteles con los que se promocionó: «una road movie etnográfica»; a su vez, este epíteto brinda las claves para abordarlo, haciendo referencia a la mixtura de la que hace gala a lo largo de su metraje y que no se circunscribe meramente a este género.

La película de Mariano Raffo narra el retorno al país de origen de la familia Quispe Cuiza, conformada por Brian, Janeth y sus tres hijos, tras ocho años de su partida. El motivo del viaje se relaciona con la búsqueda de empleados para su verdulería ubicada en el barrio de Liniers en la ciudad de Buenos Aires. La primera sección exhibe la vida cotidiana de la familia mediante escenas de corte observacional y entrevistas en las que Brian expone su agotadora rutina diaria y se dejan ver algunas discusiones familiares con su esposa. A la necesidad de la ayuda laboral como justificación del viaje, se suma la añoranza por volver a ver a sus familias. Este deseo es representado en un sueño que Brian tiene viajando en un colectivo en el que aparecen sus padres refiriéndose a la soledad en la que viven y sus anhelos de volver a verlos; se trata del primer recurso estilístico que manifiesta el carácter híbrido del documental.

La segunda sección consistirá en el retorno familiar y el reencuentro con sus familiares. Es en este punto que el documental comienza a dialogar con la road movie a partir del motivo del viaje, pero lo hace con múltiples salvedades que exhiben la apropiación de un modelo con orígenes foráneos. El carácter episódico queda patente en la parada que hacen antes de llegar a su destino final en Villazón, donde vive la familia de Janeth, y que presenta momentos de reencuentros con familiares, visitas al cementerio, un partido de fútbol, y la celebración de un cumpleaños. A su vez, esto permite la inclusión de escenas de corte etnográfico en los que se exhiben mercados y se muestra el trabajo rural. Tras la llegada a Cantón Capunata, donde concluye el viaje, se muestra 

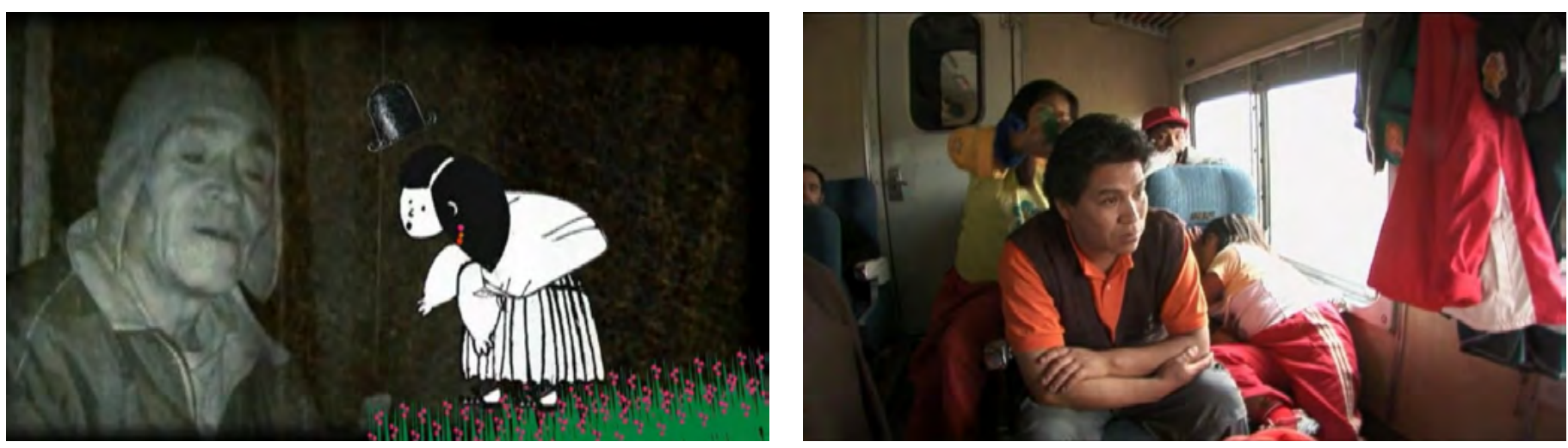

Return to Bolivia (Mariano Raffo, 2008)

la faena de un cordero, con la cámara focalizando en los rostros de los niños que no han presenciado una práctica semejante. En otra escena, el abuelo les narra a los niños una leyenda, que es representada en el filme mediante animaciones. En ellas se pone de manifiesto el choque cultural entre distintas generaciones de una misma familia que poseen distintas costumbres, producto del desarraigo.

Return to Bolivia se aleja de algunas convenciones claves del género, a partir de la ausencia del automóvil que, como señala Piedras, «representa la independencia y la autodeterminación en la road movie canónica, [y aquí] es reemplazada por el transporte público» («The Contemporary Documentary Road Movie», 223). A lo largo de su trayecto, la familia viajará en buses, tren, y micros particulares. Es por este motivo que faltan en el filme los planos de los vehículos en la ruta y el camino, y los travellings tan típicos del género, en cambio vemos solo a la familia y los paisajes filmados a través de las ventanillas. Finalmente, el regreso al hogar de la familia sin haber convencido al hermano de Brian que los acompañe a Argentina. Las últimas imágenes los muestran en su verdulería con un cartel que dice «Se necesita ayudante».

Hija (María Paz González, 2011) es un documental chileno en primera persona, una modalidad del cine de no ficción que experimentó una explosión en América Latina a principios del corriente siglo pero posee múltiples antecedentes, especialmente durante los años ochenta. A diferencia de Return to Bolivia, se trata de uno de los ejemplares que se acomoda de forma más idónea con el género que usa de intertexto, si bien señalaremos algunas cuestiones que permiten apreciar su carácter híbrido.

El filme cuenta el viaje emprendido por la realizadora, María Paz González, con su madre, Eliana, por Chile desde la ciudad de Temuco hasta Antofagasta en automóvil. El mismo posee un doble objetivo interrelacionado: buscar a la hermana de Eliana e intentar contactar al padre de María, es decir, dos intentos de sanar historias familiares. Eliana expone en una entrevista de radio en Antofagasta que fue dada en adopción de niña por sus padres biológicos, motivo por el que está buscando a su hermana para contarle la verdad, a la vez que intenta averiguar datos sobre sus progenitores. A su vez, se revela prontamente que Eliana le ha ocultado una parte

Hija (María Paz González, 2011)

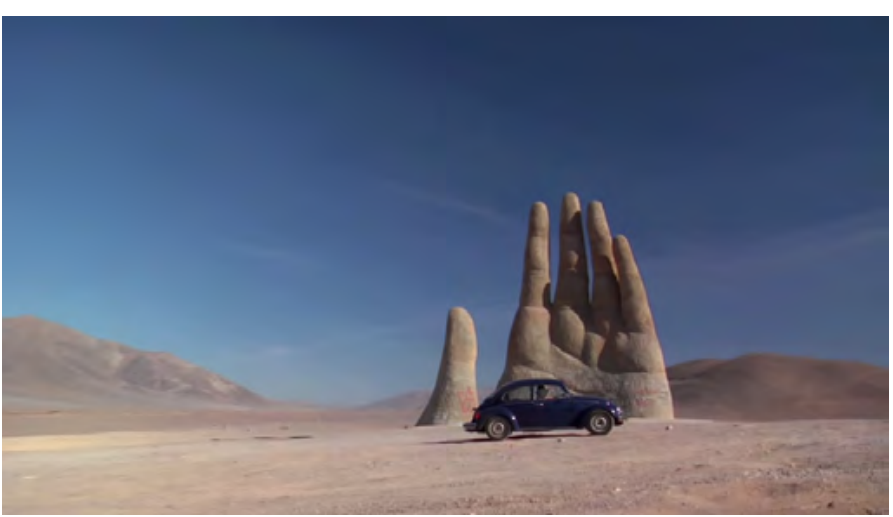


de su historia a su hija de niña, inventándole una nueva identidad tras la separación con su padre para guardar las apariencias (González no es su verdadero apellido). En este sentido, se puede apreciar nuevamente una de las temáticas propias de la road movie, el establecimiento de vínculos familiares.

De esta manera, el documental plantea una estructura narrativa clásica, con objetivos claros para sus personajes, pero abiertos a la filmación, característica típica de los «documentales de búsqueda», categoría propuesta por el teórico brasilero Jean-Claude Bernardet. En el caso de Hija, ninguna de estas búsquedas concluye de la forma esperada y el filme expone esta tensión en la conversación telefónica entre María y su padre. Tras rastrear los datos de su padre en una comisaría, donde puede ver su rostro por primera vez en la pantalla de la computadora, consigue localizarlo y le pregunta si está dispuesto a encontrarla a mitad de camino en su viaje. En un incómodo momento, escuchamos cómo su padre le solicita dinero para atender a la reunión concluyendo la conversación con ella en lágrimas. La siguiente escena, de corte performativo, presenta la voz en off de la directora leyendo el guion sobre el planeado encuentro con su padre mientras la imagen muestra una mesa vacía en un bar; así queda de manifiesto el poder de reparación que posee el cine y la diferencia entre las leyes del cine de género y el documental de búsqueda, basado en la ausencia de control.

En el caso de la madre, logra reunirse con su hermana, pero decide no revelarle sus verdaderas identidades, presentándose, en cambio, como una antigua amiga. El final de Hija no ve la restitución de esos lazos familiares, sino el fortalecimiento de los ya existentes. La última conversación entre madre e hija, filmada desde el asiento trasero, sigue así:

- ¿Qué le dijiste que andabas haciendo acá? ¿Le inventaste una historia?

- Le dije que tú eras periodista y andabas haciendo unas investigaciones y andabas con un equipo, haciendo tomas, fotos, qué se yo... Y yo te había acompañado. Que era un viaje... que habíamos salido de Temuco hasta acá.

- Entonces no le mentiste.

- No, le hice un híbrido ahí. Un híbrido.

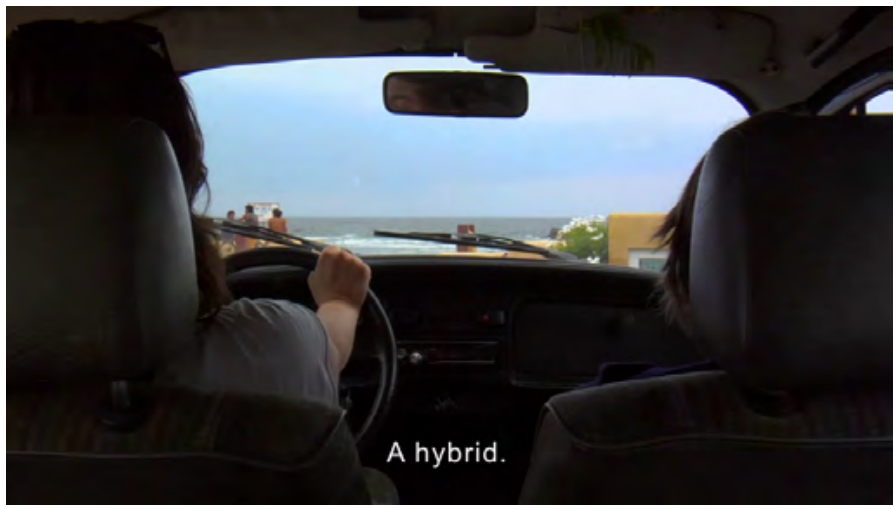

Hija (María Paz González, 2011)

A partir de estos casos podemos apreciar que el género road movie le aporta al documental una base sólida en la cual anclar sus relatos, ya sean de carácter individual o apelando a un sentido de colectividad. Una vez más, el género prueba ser una herramienta fácilmente adaptable a las distintas realidades.

\section{Píntalo de negro: el documental y el fim noir}

El último de los diálogos que abordaremos en este trabajo es el del documental noir. Una vez más, se trata de un ejemplo que ha tomado gran impulso en la actualidad, pero que posee algunos antecedentes. Probablemente el más renombrado sea The Thin Blue Line (Errol Morris, 1988) gracias a las escenas que reconstruyen el asesinato de un policía. ${ }^{8}$ En el ámbito latinoamericano, una vez más, el documental de Portillo El diablo nunca duerme resulta un exponente clave en su mezcla de road movie, film noir y melodrama narrado en primera persona.

Uno de los ejes principales en los estudios sobre el cine negro es la pregunta sobre si constituye un género o no. La principal objeción radica en que las películas que se categorizan bajo ese epíteto no fueron reconocidas

\footnotetext{
Las críticas a este tipo de reconstrucciones, como las que ensayó Francois Niney han quedado en desuso frente al cine de no ficción actual: «Demasiado fuerte, demasiado bello como para ser verdad» (468), se trata de un documental «travestido completamente en ficción» (466).
} 
como tales hasta un tiempo después, gracias al esfuerzo de la crítica francesa. Al respecto, señala Marc Vernet, «como un objeto o grupo de filmes, el film noir no pertenece a la historia del cine, pertenece a la historia de la crítica cinematográfica» (26). Este no es el ámbito para profundizar sobre este problema, pero podemos coincidir con Gonzalo Pavés en que los filmes del período clásico en Estados Unidos funcionan como guía para películas que, hoy pueden inscribirse en un género denominado film noir. Algunos de sus elementos recurrentes son el estilo fotográfico de alto contraste, la utilización de flashbacks y cámaras subjetivas, el relato en off del protagonista y personajes como el detective privado y la femme fatale. En el caso de los filmes que analizaremos a continuación, la apelación al film noir incluye tanto los elementos estructurantes como algunos iconográficos; en este sentido, el intertexto reviste un carácter más profundo que el de los casos anteriores. 33 (Kiko Goifman, 2002) y Yo no sé qué me han hecho tus ojos (Lorena Muñoz y Sergio Wolf, 2003) entablan su diálogo, nuevamente, de distintas maneras, si bien comparten tres elementos claves: la adopción de la primera persona como eje narrativo, la apropiación de elementos iconográficos y la puesta en escena de una investigación.?

En 33, el director Kiko Goifman, se planea encontrar a su madre biológica. En el apartado anterior, mencionamos la categoría de «documental de búsqueda», que Bernardet postuló justamente en relación a este film. Goifman desarrolla su investigación en tiempo presente frente a la cámara sin tener conocimiento de cuáles serán los resultados posibles. Se trata de un documental que toma el estilo noir con humor, motivo por el que el realizador se pone una serie de reglas u obstáculos: con motivo de su cumpleaños número 33, tiene esa cantidad de días para desarrollar su investigación. En el filme se hacen presentes algunas de las características mencionadas del género: la fotografía en blanco y negro de alto contraste, la narración en off y la presencia de múltiples detectives. Como señala Bernardet, «su problema per-

\footnotetext{
Algunos otros exponentes de esta modalidad son Imagen final (Andrés Habegger, 2008), El rascacielos latino (Sebastián Schindel, 2012), Agosto final (Eduardo Sánchez, 2016) y el falso documental Los corroboradores (Luis Bernárdez, 2018).
}

sonal pasa por el molde de un género industrial hípercodificado, que es el film noir, donde todo coincidió con el perfil de su película (el color, la tonalidad, las calles nocturnas, la lluvia, el asfalto, los detectives, etc.)» (123).

El filme presenta múltiples referencias visuales y citas a ejemplos del género detectivesco. Desde los bustos de Sherlock Holmes que se exhiben el escritorio de un detective privado que aconseja a Goifman, la cita del escritor de Dashiell Hammett que abre la película hasta la mención que hace en el relato en off al filme El balcón maltés (John Huston, 1941) basado, justamente, en la novela de aquel autor: tras esconder un papel con los datos de su nacimiento bajo un pavo de cerámica dice «El pavo sería mi halcón maltés». A su vez, señala las diferencias entre los personajes de estas ficciones y él; después de una noche en la que bebe alcohol, dice que recuerda «la literatura clásica de detectives [en la que] que solían beber y despertarse bien a la mañana siguiente. Mi cuerpo no tenía -la reacción deseada».

El realizador/detective prueba múltiples estrategias para intentar llegar a la verdad: entrevistas a familiares, al portero del edificio donde lo entregaron, visita la casa donde nació y revisa archivos, visita a una médium pero ninguno le ofrece revelaciones. Un detective le sugiere pinchar el teléfono de su madre adoptiva, que le «lave el cerebro» atosigándola con preguntas con el objetivo

33 (Kiko Goifman, 2002)

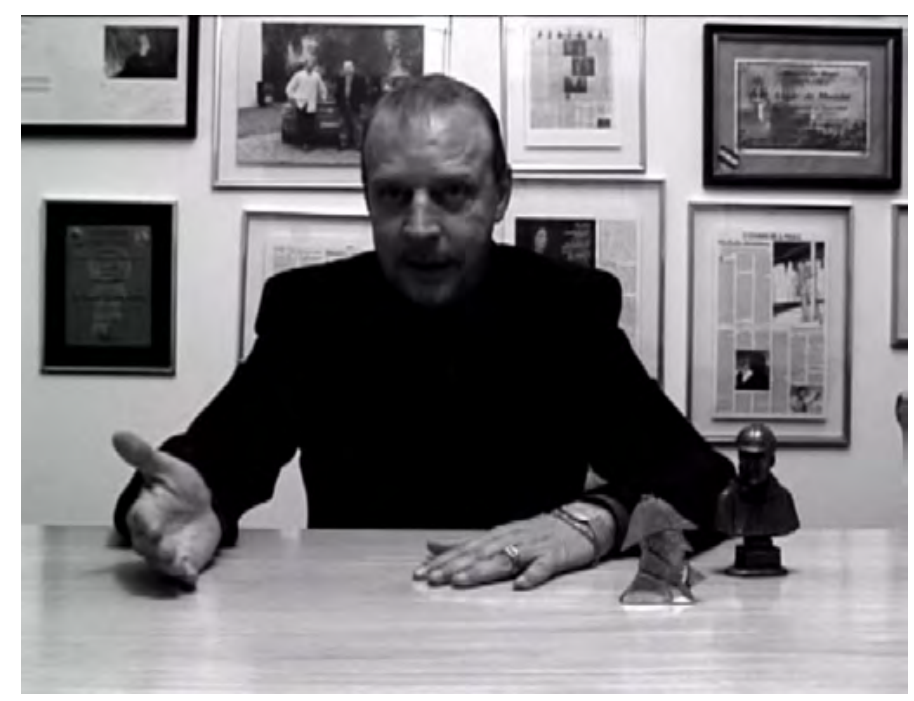




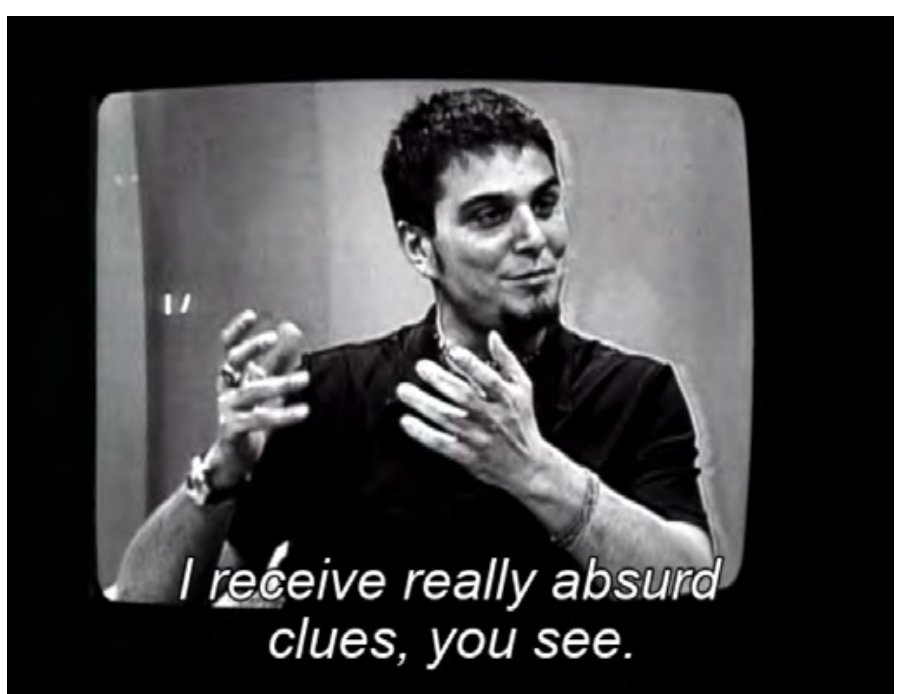

33 (Kiko Goifman, 2002)

que llame a alguien y le cuente lo que sabe. En este punto, Goifman manifiesta preocupación por herir a una persona, uno de los dilemas éticos del documental que lo separa de la ficción. Finalmente, decide utilizar los medios de comunicación y exhibe su proyecto en la televisión esperando que alguien lo contacte. El hijo de la mujer que se ofreció de intermediaria en la adopción lo llama, y en una entrevista le dice que su madre murió y con ella ese secreto. 33 concluye con la voz de Goifman en off:

El sentimiento fue el de muchos de los detectives creados por Dashiel Hammett, Paul Auster, James Ellroy o Manuel Vázquez Montalbán: Cuando llega el cliente paga la suma acordada y se detiene la búsqueda. El cliente que creé fue el tiempo. La búsqueda, si por casualidad continúa, no será pública.

Yo no sé qué me han becho tus ojos también se estructura en torno a una investigación llevada a cabo frente a cámara por uno de sus directores, Sergio Wolf, quien ofrece una interpretación de sí mismo. La pesquisa gira en torno a la figura de
Ada Falcón, una popular cantante de tangos y actriz de la década del treinta que dejó de lado la fama y se internó en un convento. Siguiendo la clasificación de los usos de la primera persona en el documental ofrecida por Pablo Piedras (El documental en primera persona), se trata de una primera persona epidérmica, en tanto el objeto de su investigación no se encuentra relacionado a su biografía, sino que se trata de una excusa narrativa. Wolf como personaje se construye iconográficamente a la manera de un detective privado del cine negro estadounidense, utilizando un sobretodo. Thomas Sobchack señala en relación al cine de género que:

la iconografía, al igual que las situaciones familiares de la trama y los personajes estereotipados, proporciona una forma abreviada de comunicaciones mutuamente reconocibles sobre las que ni el cineasta ni el público necesitan reflexionar (...) La caracterización en una película de género a menudo utiliza la abreviatura de iconografía. Conocemos a una persona por lo que viste y no por lo que dice y hace (106-107).

Mientras efectúa unas llamadas telefónicas para averiguar sobre el filme que protagonizó Falcón que se encuentra perdido, el plano lo presenta a Wolf con una fotografía de la actriz colgando de la cortina. La composición del mismo remite a una de las imágenes más
Yo no sé qué me han hecho tus ojos (Lorena Muñoz y Sergio Wolf, 2003)

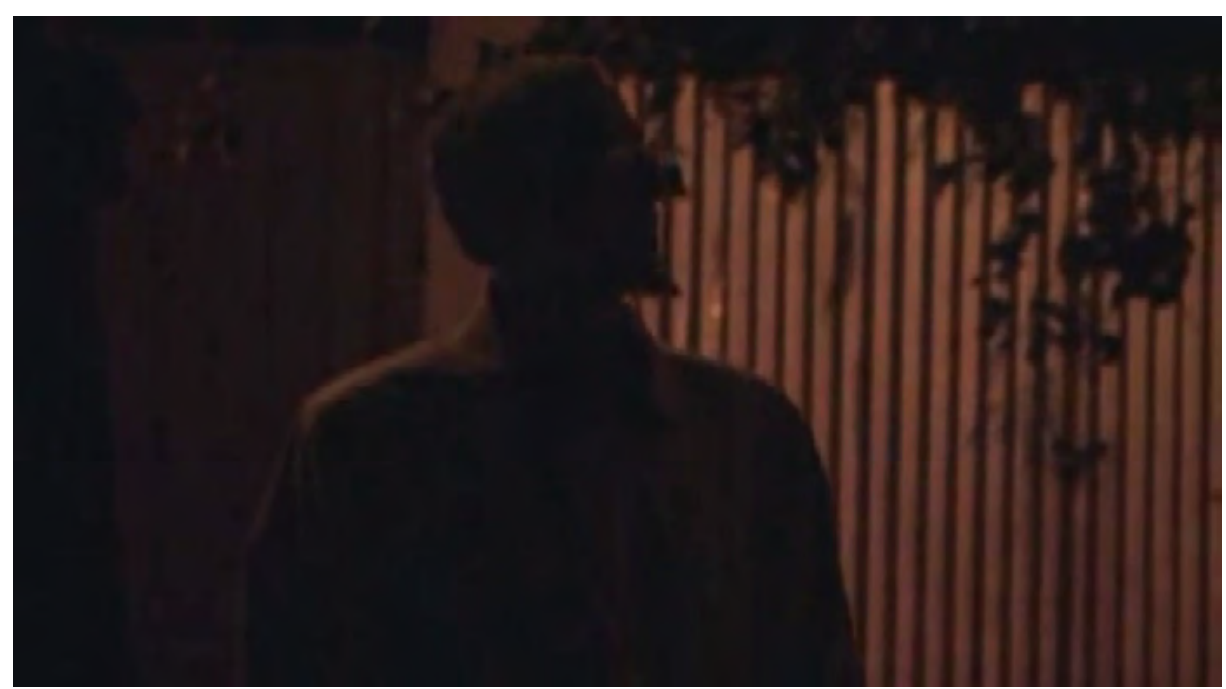




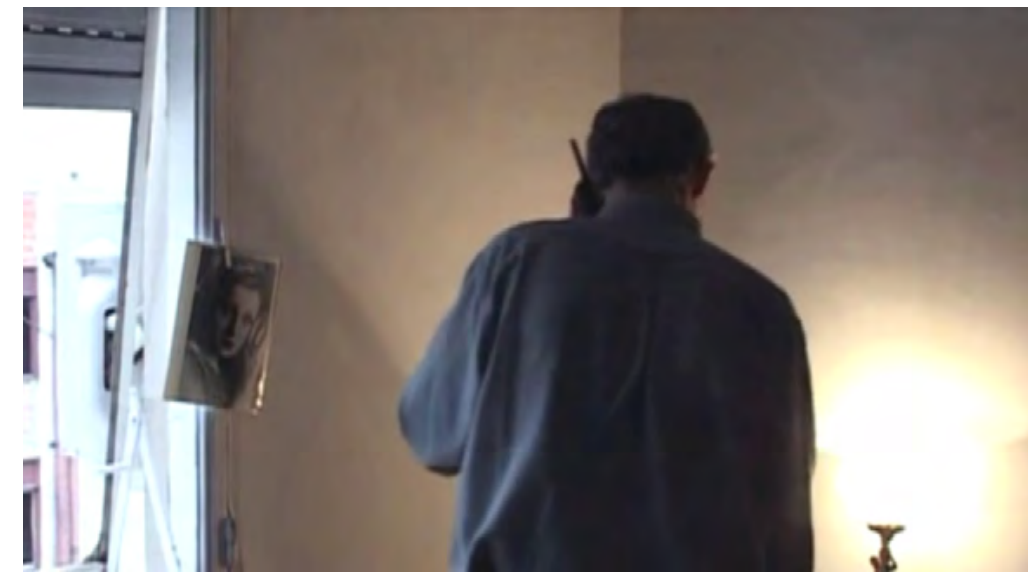

Yo no sé qué me han hecho tus ojos (Lorena Muñoz y Sergio Wolf, 2003)

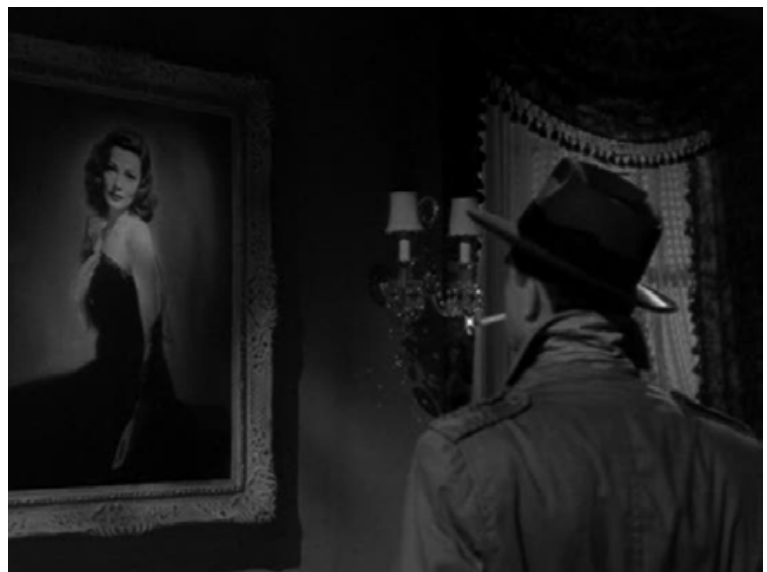

Laura (Otto Preminger, 1944) icónicas del cine negro: el detective obsesionado con el cuadro de Laura (Otto Preminger, 1944).

A su vez, Wolf utiliza la narración en off, un procedimiento, como ya mencionamos en relación a 33, recurrente del cine negro. Mediante ella va uniendo la información recopilada a la vez que busca justificar la investigación del personaje:

Dejar todo por una convicción, eso es lo que me obsesiona, ir al revés de lo que dice la época, la cruzada espiritual, eso es lo que me une a la historia de Ada. Hay muchas películas posibles sobre las vidas de las cancionistas, pero la de Ada Falcón es la única que me invade, la única que me intriga, la única que vuelve una vez, otra vez, otra vez. Es la historia la que no me deja, no soy yo el que no puedo dejarla.

Como señala Daniel Link, el detective «inviste de sentido la realidad brutal de los hechos, transformando en indicios las cosas, correlacionando información que aislada carece de valor, estableciendo series y órdenes de significados que organiza en campos» (7).

El documental se divide claramente en dos partes: la primera es la que se articula en relación al cine negro, la segunda consiste en una entrevista a Falcón en sus últimos días de vida en un convento en la provincia de Córdoba. Si bien la narración del filme transcurre en un tiempo presente con el espectador asistiendo a la pesquisa de Wolf, el rodaje de la entrevista tomó lugar primero. Este es un punto central para marcar las dife- rencias en relación al documental de Goifman, que se caracterizaba por la apertura a lo desconocido, mientras que aquí las escenas que remiten al género en cuestión son pensadas desde una puesta en escena controlada.

El film noir brinda una matriz génerica clave tanto en la estructura de los relatos, a partir de la noción del misterio, como en la generación de imágenes. En ambos casos podemos apreciar un tono lúdico en el intertexto que permite al documental alejarse de la noción del discurso de sobriedad.

\section{Conclusiones}

A lo largo de este texto pudimos observar en el corpus abordado una multiplicidad de formas en las que los documentales se han apropiado del sistema de géneros sin, por eso, negar su carácter. En el caso del cine de terror, los filmes utilizan principalmente elementos iconográficos y procedimientos estilísticos que buscan un efecto de shock en el espectador. En Alucardos podemos apreciar también las maneras en la que el cine de género puede impactar en la biografía de los seres humanos, moldeando sus deseos, actitudes y comportamientos. El intertexto con la road movie, por otro lado, suele basarse más en la apropiación de estructuras narrativas y temáticas. La noción de movilidad, tan cara al documental 
contemporáneo, y el tópico del viaje suponen la excusa perfecta para esa combinación. Una vez más, podemos argumentar que la estructura génerica le permite en el caso de la realizadora de Hija encarar una importante parte de su historia e intentar brindarle un cierre. Por último, los dos ejemplos del documental noir, con sus respectivas características, nos permiten apreciar una fusión sintáctica-semántica en la relación con su intertexto. Tanto la iconografía como las estructuras del género son recuperadas en estos documentales en primera persona.

En una gran parte de los ejemplos analizados, también pudimos observar que la noción de la imaginación juega un rol importante: escenas que representan sueños, lecturas de guiones que no llegaron a concretarse en la realidad, reconstrucciones de eventos que quizás nunca sucedieron. El poder del cine y los géneros también permite escenificar las subjetividades de los sujetos.

Si bien poseen múltiples elementos fijos que se repiten de obra en obra, las fronteras de los géneros han probado ser elásticas asegurando su continuidad a la vez que se permiten atravesar distintas culturas sin perder su atractivo. En definitiva, los géneros funcionan como estrategias de mediación y codificación entre los sujetos y el mundo real; frente a la inconmensurabilidad de la realidad, la posibilidad de organizar y hacer familiar lo desconocido supone un atractivo innegable para el documental.

\section{Bibliografía}

Altman, Rick. Los géneros cinematográficos. Barcelona: Paidós, 2000.

Arenillas, María Guadalupe \& Michael J. Lazzara. «Introduction: Latin American Documentary Film in the New Millennium». Latin American Documentary Film in the New Millennium. Eds. Arenillas, María Guadalupe \& Michael J. Lazzara. New York, Palgrave Macmillan, 2016, pp. 1-19.

Bernardet, Jean-Claude. «Documentales de búsqueda: 33 y Pasaporte húngaro». El cine de lo real. Eds. Labaki, Amir \& María Dora Mourão. Buenos Aires: Colihue, 2011, pp- 117-128.
Chanan, Michael. «The Space between Fiction and Documentary in Latin American Cinema: Notes toward a Genealogy». Visual Synergies in Fiction and Documentary Film from Latin America. Ed. Haddu, Miriam \& Joanna Page. New York, Palgrave Macmillan, pp. 15-24.

Corrigan, Timothy. A Cinema without Walls. Movies and Culture after Vietnam. Londres-New York, Routledge, 1991

Flaherty, Robert. «La función del documental». Textos y manifiestos del cine. Ed. Romaguera i Ramió \& Homero Alsina Thevenet. Madrid, Cátedra, 1993, pp. 139-147.

Hill, Annette. Restyling Factual TV. News, Documentary and Reality Television. New York, Routledge, 2007.

Jameson, Fredric. «Globalization and hybridization». World Cinemas, Transnational Perspectives. Ed. Durovičová, Natasa \& Kathleen Elizabeth Newman. Londres-New York, Routledge, 2010, pp. 315-319.

Lebow, Alisa. «The unwar film». A Companion to Contemporary Documentary Film. Ed. Juhasz, Alexandra \& Alisa Lebow. Oxford, Wiley Blackwell, 2015, pp. 454-474.

Lie, Nadia \& Pablo Piedras. «Identidad y movilidad en el cine documental latinoamericano contemporáneo: Familia tipo (2009) e Hija (2011)». Confluencia, Vol. 30, No 1, 2014, pp. 72-86. https://doi.org/10.1353/ cnf.2014.0009 Recuperado el 10 de octubre de 2020.

Link, Daniel. «El juego silencioso de los cautos». El Juego de los Cautos. La literatura policial: De Poe al caso Giubileo. Comp. Link, Daniel. Buenos Aires, La marca editoria, 1992, pp. 5-11.

Miller, Carolyn R. «Genre as social action» Quarterly Journal of Speech, 70, 1984, pp. 151-167. Recuperado el 10 de octubre de 2020.

Niney, François. La prueba de lo real en la pantalla: ensayo sobre el principio de realidad documental. México, UNAMCUEC, 2009.

Orgeron, Devin. Road Movies. From Muybridge and Méliès to Lynch and Kiarostami. New York, Palgrave Macmillan, 2008.

Pavés, Gonzalo M. El cine negro de la RKO. En el corazón de las tinieblas. Madrid, T\&B Editores, 2003. 
Piedras, Pablo. «The Contemporary Documentary Road Movie in Latin America: Issues on Mobility, Displacement, and Autobiography». The Latin American Road Movie. Ed. Verónica Garibotto \& Jorge Pérez. New York: Palgrave Macmillan, 2016.

Piedras, Pablo. El cine documental en primera persona. Buenos Aires, Paidós, 2014.

Rancière, Jacques. La fábula cinematográfica. Reflexiones sobre la ficción en el cine. Barcelona: Paidós, 2005.

Sobchack, Thomas. «Genre Film: A Classical Experience». Film Genre Reader II. Ed. Barry Keith Grant. Austin: University of Texas Press, 1995, pp. 114-128
Staiger, Janet. « Hybrid or Inbred: The Purity Hypothesis and Hollywood Genre

History». Film Genre Reader IV. Ed. Barry Keith Grant. Austin: University of Texas Press, 2012, pp. 203-217 Vernet, Marc. «Film noir on the Edge of Doom». Shades of Noir. A reader. Ed. Copjec, Joan. Londres-New York, Verso, pp. 1-32.

Vertov, Dziga. «Nosotros (variante del Manifiesto)». Textos y manifiestos del cine. Ed. Romaguera i Ramió \& Homero Alsina Thevenet. Madrid, Cátedra, 1993, pp. 37-40. 